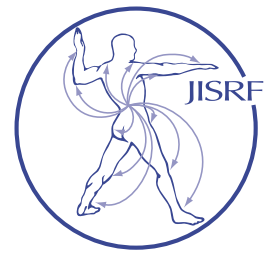

\title{
Simulator Study of MOM using Steep-cup Flexion - A Clinically Relevant Incorporation of Intermittent Edge-loading
}

Clarke I.C. ${ }^{1}$, Shelton J.C. ${ }^{2}$, Bowsher J.G. ${ }^{3}$, Savisaar $C^{4}$, Donaldson $T^{5}$

\section{Abstract}

Background: Adverse-wear phenomenon in metal-onmetal (MOM) arthroplasty has been attributed to "edgeloading" of the CoCr cups. Simulator studies of steeplyinclined cups run in the 'Anatomic-cup' model represented many variations in design and test parameters with no coherent rationale. We created an algorithm to synthesize MOM test parameters and noted that wear areas typically averaged only $10-15 \%$ of cup surface. In contrast, retrievals showed wear areas extending to $60 \%$ of cup surface. We hypothesized that MOM wear studies run in the orbital hip simulator with the 'Inverted-cup' model would, (i) differentiate normal-loading versus edge-loading, (ii) demonstrate cup wear areas x3.8-times larger than on femoral heads, cover $30 \%$ of cup surface, and (iii) double the wearrates measured in prior Anatomic-cup study.

Methods: Edge-loading occurs when the cup rim is allowed to truncate the habitual wear area that provides optimal tribological conditions. A MOM algorithm was developed to synthesize relevant test parameters. The $60 \mathrm{~mm}$ MOM bearings donated for this study were run in an orbital hip simulator using the Inverted-cup model. Tests \#1 and $\# 2$ to one million cycles (1-Mc) duration assessed wear at peak cup inclinations $40^{\circ}$ and $50^{\circ}$. Test $\# 3$ evaluated edgeloading with peak cup inclinations achieving $70^{\circ}(5-\mathrm{Mc}$ duration).

Results: Wear areas in Inverted-cups averaged $1663 \mathrm{~mm} 2$ in tests \#1 and 2, were fully contained within cup rims, and covered $30 \%$ of cup surface as predicted by algorithm. Test- 3 with $70^{\circ}$ cup inclination produced the predicted edge-loading with volumetric wear-rates averaging $2 \mathrm{~mm} 3 / \mathrm{Mc}$, approximately 5-fold greater wear than prior Anatomic-cup study.

Discussion and Conclusions: Simulator studies of steep-cup mechanisms necessitate production of clinically-relevant wear-patterns such that the biomechanical and tribological functionality is respected. As an aid to steeply-inclined cup analyses, the MOM algorithm allowed integration of confounding test parameters. The algorithm successfully differentiated between "normal" and "edge loaded" cups and the MOM wear areas were as predicted for three cup inclinations. Also as predicted, wear-patterns in Inverted-cup model exactly reversed those of the Anatomic-cup model. Even with only intermittent edge-loading, Test-3 produced 5-fold greater wear than our prior Anatomic study.

Clinical Significance: The Inverted-cup simulator model successfully mobilized the cup to produce larger wear areas that were more representative of those in-vivo and therefore reproduced more realistic test conditions for studies of edge-loaded cups.

Keywords: hip arthroplasty, MOM bearings, edge loading, simulator, wear

Level of Evidence: AAOS Therapeutic Level II

Educational Value \& Significance: JISRF Level B 


\section{Background}

Laboratory wear predictions of total hip arthroplasty (THA) have come under frequent criticism, partially because they present only a limited simulation of many possible clinical conditions (Fig. 1A). For example, international guidelines [1] only specify one inclination for the acetabular cup $\left(30^{\circ}\right)$ in the hip simulator [Fig. 1B], this believed analogous to a $45^{\circ}$ cup inclination in patients (Fig. 1A). This test configuration, referred to as the 'Anatomic' mode (Fig. 1B), represents an ideal wear model and has been the standard simulator test for almost 2 decades. Various studies demonstrated MOM wear to be satisfactorily low over the specified 5-million cycle test (Fig. 2A: 5-Mc test, cup inclination $\left.35^{\circ}\right)$. [르, $\left.\underline{3}, \underline{4}\right]$

The revival of large MOM hip bearings began in the mid 1990's $[\underline{5}, \underline{6}]$ and the first warnings of adverse wear with $\mathrm{CoCr}$ cups started appearing between 2006 and 2008 [ㄱ, $, 2,2]$. Subsequent clinical and retrieval studies demonstrated that steeply-inclined $\mathrm{CoCr}$ cups were particularly at risk for adverse wear, believed due to "edge loading" of the head against the rim of the acetabular cup $[10,11]$. Simulator studies then explored the effects of steeply-inclined cups. In one study of $38.5 \mathrm{~mm}$ MOM run with $35^{\circ}$ and $50^{\circ}$ cup inclinations, wear-rates averaged 3.3 and $11 \mathrm{~mm}^{3} / \mathrm{Mc}$, respectively [12]. In this 2-Mc test, the steeper cups demonstrated a 3.3-fold wear increase overall. In a similar study comparing $48 \mathrm{~mm}$ MOM run with $35^{\circ}$ and $65^{\circ}$ cup inclinations, wear-rates averaged 2.5 and $19.5 \mathrm{~mm} 3 / \mathrm{Mc}$, respectively [13]. Here the steeper cups presented a 7.8-fold increase over controls. However notable in two 5-Mc studies was that the wear with steeper cups appeared only double that of controls (Fig. 2B). [2, 14] These exploratory studies included many confounding cup designs, diameters, metallurgy, and test parameters. Thus, no coherent theory was developed to explain such variations in wear performance of MOM bearings.

Using data from our prior $60 \mathrm{~mm}$ MOM retrieval study [15], we developed an algorithm to integrate variations included in cup design, head diameter, and cup inclination. The key to the algorithm was an equation that defined size of wear-patterns on $\mathrm{CoCr}$ heads and cups. [16] In our prior Anatomic study, wear-patterns averaged $1668 \mathrm{~mm}^{2}$ on heads and $442 \mathrm{~mm}^{2}$ on cups, these data providing an experimental ratio of 3.77 for wear areas [17]. The theoretical wear-pattern ratio (x3.87) calculated using the cam design of the orbital simulator validated these data. It was also noted that the Anatomic simulator test produced cup wear-patterns that represented only $10-15 \%$ of the nominal

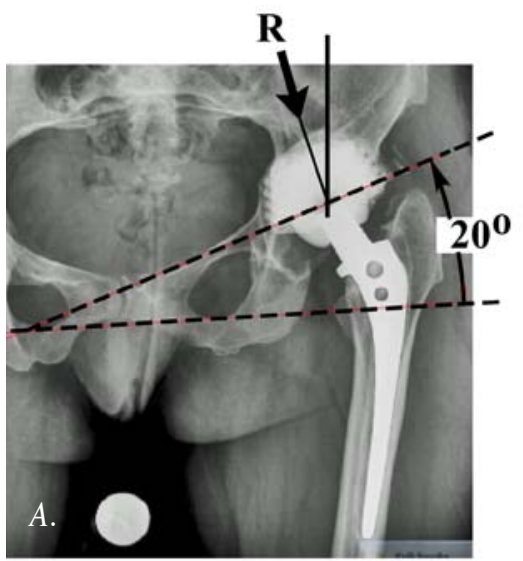

In vivo hip anatomy

Figures $1 A \& B$.

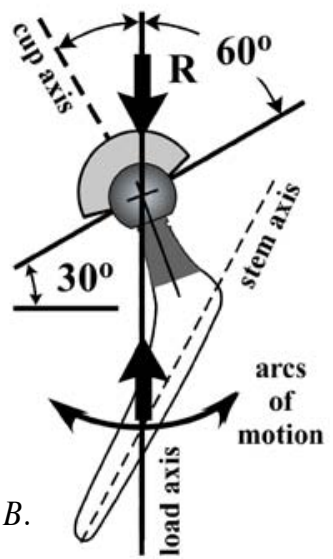

Simulator configuration
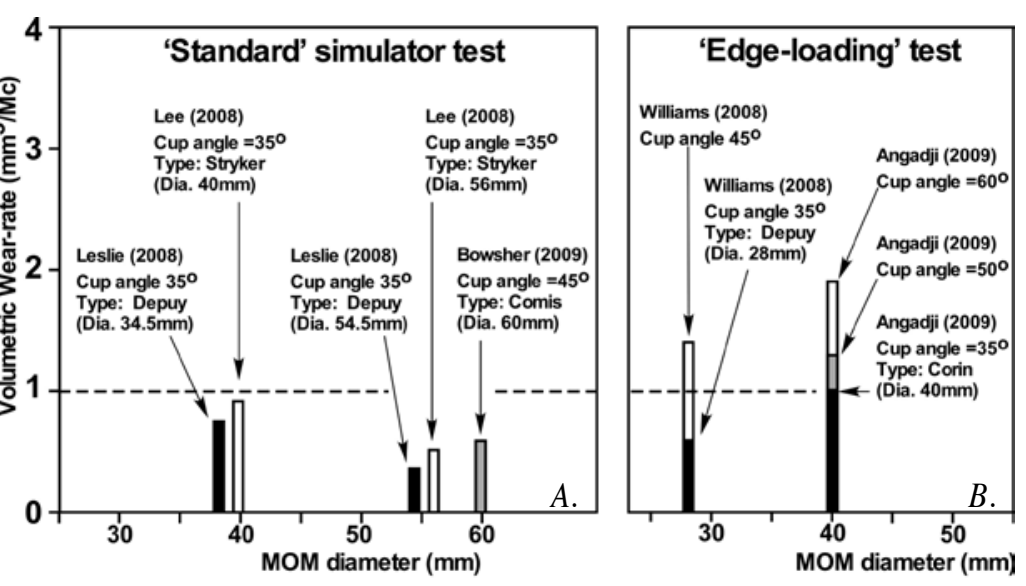

Figures $2 A \& B$.

hemispherical surface, defined here as the hemi-cup ratio (Table 1). [15] In contrast, retrieval studies showed hemicup ratios extended 50-60\% in-vivo, i.e. were much larger than produced in contemporary simulator studies $[\underline{15}, \underline{18}]$. This difference would not be readily apparent in the standard simulator test (Fig. 1B) but would clearly be an important parameter when simulating edge-wear in steeplyinclined cups.

Table 1. Cup wear areas in simulators at 5-Mc (ISO-14242), ranked by MOM diameter.

\begin{tabular}{|l|c|c|c|c|c|}
\hline Study & $\begin{array}{c}\text { Diameter } \\
(\mathbf{m m})\end{array}$ & $\begin{array}{c}\text { Clearance } \\
(\boldsymbol{\mu m})\end{array}$ & $\begin{array}{c}\text { Hemi- } \\
\text { area } \\
\left(\mathbf{m m}^{2}\right)\end{array}$ & $\begin{array}{c}\text { Wear } \\
\mathbf{a r e a} \\
\left(\mathbf{m m}^{2}\right)\end{array}$ & $\mathbf{H e m i \%}$ \\
\hline Leslie 2008 & 38.5 & 126 & 2328 & 429 & $18 \%$ \\
\hline Lee 2008 & 40 & 400 & 2513 & 364 & $14 \%$ \\
\hline Lee 2008 & 40 & 150 & 2513 & 383 & $15 \%$ \\
\hline Leslie 2008 & 54.5 & 111 & 4666 & 474 & $10 \%$ \\
\hline Lee 2008 & 56 & 400 & 4926 & 419 & $9 \%$ \\
\hline Lee 2008 & 56 & 150 & 4926 & 416 & $8 \%$ \\
\hline $\begin{array}{l}\text { Bowsher } \\
\text { 2009 }\end{array}$ & 60 & 245 & 5655 & 442 & $8 \%$ \\
\hline
\end{tabular}


Edge-loading occurs when the cup rim truncates what would be the normal, habitually worn area. Thus, a clinically relevant simulation of edge-wear effects necessitates a realistic wear pattern for the cup. Simulator mechanics creates the larger 'distributed' wear-pattern on the mobile bearing, this being the femoral head in the Anatomic test mode (Fig. 1B). The alternative 'Inverted cup' strategy would make the cup oscillate such that the larger wear-pattern would have a hemi-cup ratio of approximately $30 \%$ [15]. The first published studies of wear in 2nd generation MOM were run in this 'Inverted' test mode (Fig. 3) using MOM bearings of $28 \mathrm{~mm}$ and $45 \mathrm{~mm}$ diameter. [19, $\underline{20}]$ Although not measured in these early studies, distributed wear-patterns would have been produced in the cups. [21] The goal in this MOM simulator study was to demonstrate that steeply-inclined cups could be run successfully in "Inverted" test mode (Fig. 3). The hypotheses were that, (i) the MOS-algorithm would differentiate between "normal" and "edge-loading" conditions, (ii) wear patterns in $60 \mathrm{~mm}$ cups run Inverted to $1 \mathrm{Mc}$ duration with no risk of edge-loading would be 3.8 times larger than on their mating heads, and (iii) cups run Inverted under edge-loading conditions to 5-Mc would double the wear-rates measured in the Anatomic study.
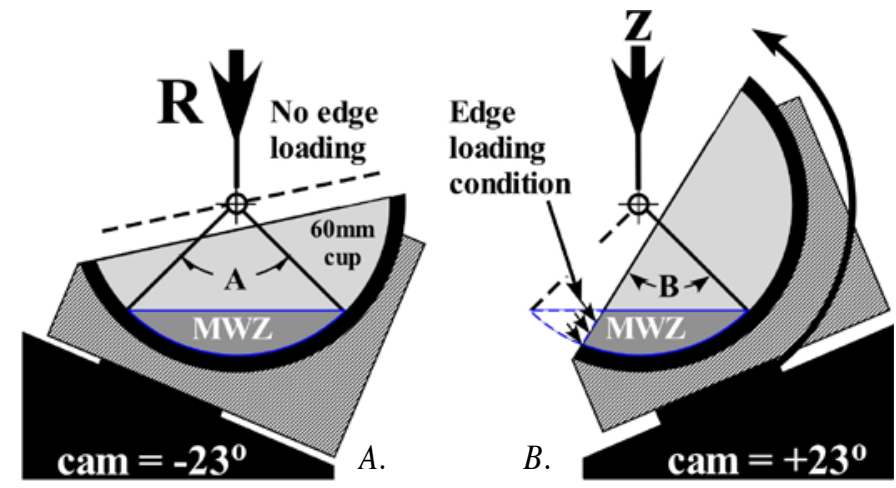

Figures $3 A \& B$

\section{Methods}

The hip simulator was identical to that used in our prior Anatomic study (Shore Western, Monrovia, CA) and our test methods duplicated that work. [17] Three tests were conducted with $60 \mathrm{~mm}$ MOM bearings (donated for research, DJOGlobal, Austin TX) with 1-Mc tests \#1 and \#2 run to to assess the wear-pattern shifting with steeper cup inclinations but with no edge-loading (Table 2). Test \#3 ( $\mathrm{N}=4$ $\mathrm{MOM}$ ) was run to 5-million cycles with cup mounting-angle (L) set to $47^{\circ}$ such that the cam mechanism created minimum/maximum cup inclinations of $24^{\circ}$ and $70^{\circ}$ (Fig. 3 ). Our prediction was that the cup wear-pattern would be truncated by $7.8^{\circ}$, this representing an edge-wear condition of $9 \%$ in test \#3 (Appendix A).

Table 2. Algorithm parameters for 60mm MOM.

\begin{tabular}{|l|l|l|l|l|}
\hline$\#$ & Parameter & Test-1 & Test-2 & Test-3 \\
\hline 1 & Cup rim profile angle (P) & 5.6 & 5.6 & 5.6 \\
\hline 2 & Angle subtending wear area (A) & 90.4 & 90.4 & 90.4 \\
\hline 4 & angle (P+A/2) & 50.8 & 50.8 & 50.8 \\
\hline 5 & Inclination angles (L) & 17.0 & 27 & 47 \\
\hline 6 & Angle (L+P+A/2) & 67.8 & 77.8 & 97.8 \\
\hline 7 & MOS angle & 22.2 & 12.2 & -7.8 \\
\hline 8 & Edge wear (EW\%) & none & none & $-9 \%$ \\
\hline
\end{tabular}

Cup adaptors were machined from Polyacetal with locking rings added to secure the steeply-inclined cups (Fig. 6). Each assembly was attached to a steel baseplate that housed a Plexiglas cylinder acting as lubricant chamber $(450 \mathrm{ml})$. Wear-patterns and weight-loss data were measured at 0.5 -million cycle intervals to $5 \mathrm{Mc}$ duration. Areas of wear on heads and cups were identified visually and by light microscopy, stained red, and taped where necessary to minimize reflections during photography.

\section{Results}

Cup wear patterns in tests \#1 and 2 were fully contained within cup rims as predicted by the MOS-algorithm and averaged $1663 \mathrm{~mm}^{2}$ and $1571 \mathrm{~mm}^{2}$ areas, respectively with $<3 \%$ variation about these means. The small MOS-angle in test- 2 was difficult to measure, approximately $5.3^{\circ}$ (Fig. 5B). The wear-patterns in study-1 (Fig. 5A) were selected as controls and demonstrated a $15.4^{\circ}$ margin of safety (Table 3). Cup wear patterns were distinct and described by an included-angle of $90.2^{\circ}$ (angle-A) subtended by a
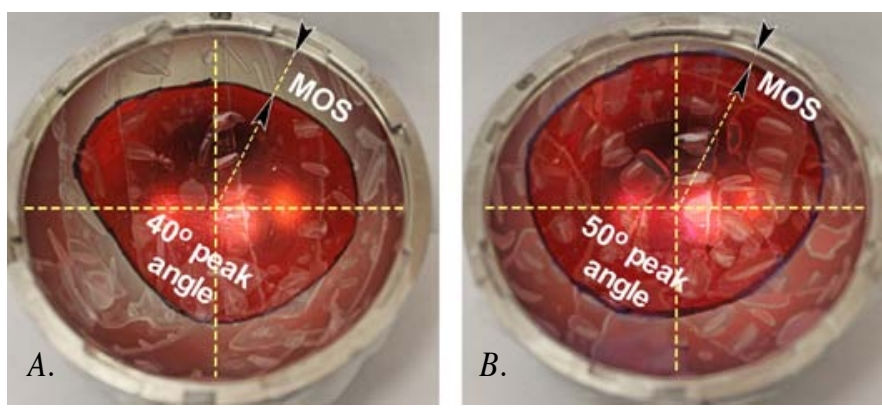

Figures $5 A \& B$. 
Table 3. Cup wear areas using $40^{\circ}$ peak inclination (test-1: 1Mc).

\begin{tabular}{|l|c|c|c|}
\hline Test-1 & Cup-1 & Cup-2 & Averages \\
\hline NWZ angle (N) & 55.6 & 55.6 & 55.6 \\
\hline MWZ angle (A) & 91.6 & 88.9 & 90.2 \\
\hline MOS angle (MOS) & 14.0 & 16.7 & 15.4 \\
\hline Calculated MWZ area & & & 1663 \\
\hline Hemi-area (60mm cup) & & & 5655 \\
\hline Hemi-area ratio (\%) & & & $29.4 \%$ \\
\hline
\end{tabular}

wear area of $1663 \mathrm{~mm}^{2}$ with corresponding hemi-area ratio $29.4 \%$. The femoral-head wear patterns at $1 \mathrm{Mc}$ duration were too indistinct to measure.

Cup weight-loss from wear over 5-Mc trended fairly linearly to beyond $50 \mathrm{mg}$. Transient weight-gains were evident at $0.25 \mathrm{Mc}$ duration (Fig. 6A: flag-1,15mg) and at 2.5$3 \mathrm{Mc}$ (flag 2). These fluctuations were due to build-up of protein contaminants inside the cups and were disregarded. Also noted was that cup \#4 sustained damage at $0.75 \mathrm{Mc}$ and was not included in the analysis (flag-4: malfunction of simulator cam-bearing).

Head weight-loss trends showed run-in variations up
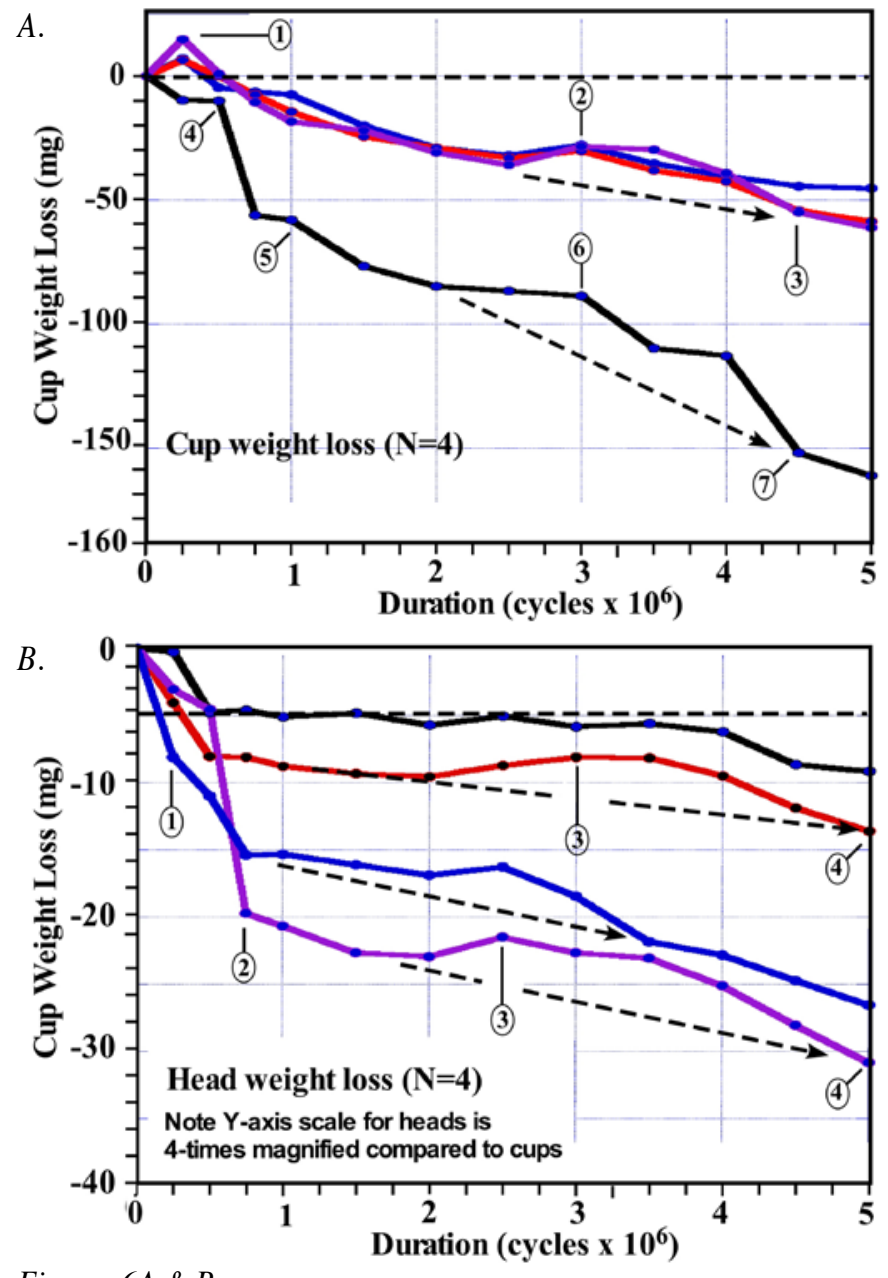

Figures $6 A \& B$.

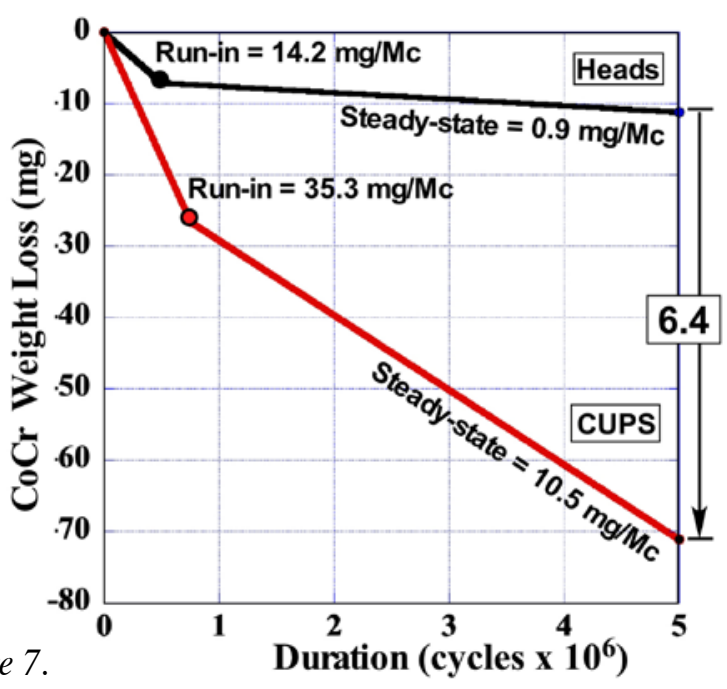

to $0.75 \mathrm{Mc}$ (Fig. 6B: flags-1, 2). Transient weight-gains were also evident on heads (Fig. 6B: flags 3-4). Statistical analysis over 0.75 to $5 \mathrm{Mc}$ for heads favored a steadystate weight-loss averaging $0.9 \mathrm{mg} / \mathrm{Mc}$. The corresponding steady-state cup trend averaging $10.5 \mathrm{mg} / \mathrm{Mc}$ was $11.7-$ fold greater than for heads. By 5-million cycles duration, the total weight-loss in heads and cups amounted to 11.2 and $71.1 \mathrm{mg}$, respectively, i.e. 6.4-fold greater in cups (Fig. 7). The corresponding volumetric wear-rates for run-in and steady-state phases averaged $6 \mathrm{~mm} 3 / \mathrm{Mc}$ and $1.4 \mathrm{~mm} 3 / \mathrm{Mc}$, respectively. These represented an overall wear-rate of approximately $2 \mathrm{~mm} 3 / \mathrm{Mc}$.

Steep-cup test-3 $\left(70^{\circ}\right.$ inclination) was predicated on truncating the normal wear-pattern by $7.8^{\circ}$ to produce edge-loading in the cup. The main wear pattern (MWZ) clearly showed the effects of edge-loading produced (Fig. 8). Wear-patterns on femoral heads were faint, difficult to characterize and quite variable. Heads 1 and 4 were selected as the best representation at $2.5 \mathrm{Mc}$ duration, providing wear-pattern areas of $330 \mathrm{~mm}^{2}$ and $588 \mathrm{~mm}^{2}$ (approximated to $460 \mathrm{~mm}^{2}$ ).

\section{Discussion}

This appears to be the first simulator study using a mathematical approach to define edge-loading in cups. The MOS-algorithm predicted that $60 \mathrm{~mm}$ cups would have a 'critical' inclination angle of $62^{\circ}$ (Appendix A). Tests 1 and 2 at $1 \mathrm{Mc}$ duration (peak inclinations $40^{\circ} / 50^{\circ}$ ) showed wear patterns did not extend to the cup rims. In contrast, test-3 with $70^{\circ}$ peak inclination produced edge loading as confirmed by the truncation of the wear patterns (Fig. 8). These data satisfied the first hypothesis that the MOS-algorithm would differentiate between "ideal" and "edge-loading" conditions. 
There was no precedent for this simulator edge-loading study in 'Inverted' mode. The test validity was established by comparing areas worn in Inverted cups to those on heads run in 'Anatomic' test mode. Inverted cup areas (wear pattern $=1663 \mathrm{~mm}^{2}$ ) corresponded almost exactly

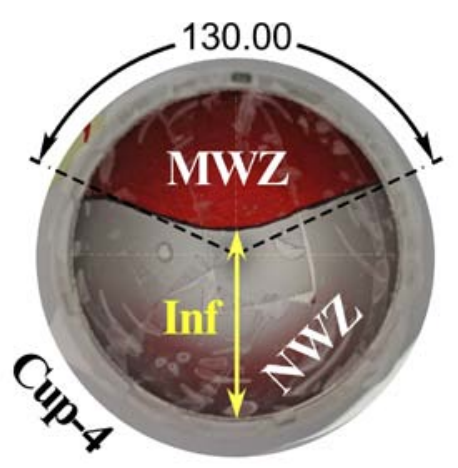

Figure 8. to Anatomic head areas (wear pattern $=1668 \mathrm{~mm}^{2}$ ). This established our overall thesis, that running hip bearings in an Inverted test simply reversed the wear patterns produced in the Anatomic test. A governing criterion for steep-cup simulations is the cup wear-patterns should be representative of those in MOM retrieval studies. This study increased cup wear-patterns from a low of $8 \%$ in Anatomic mode to $29 \%$ in Inverted mode but this was still not as high as measured in retrieved cups. Possibly this reflects patients having much greater gait complexity compared to simulators using a fixed $45-46^{\circ}$ flexion arc.

MOM bearings typically show high wear during initial run-in phase, and then generally transition to a lower wearrate within 1-million cycles. This occurs when head and cup wear-patterns enlarge enough to support optimal tribological conditions. Edge-loading produces truncation of normal wear patterns (compare Figs. 5 and 8) such that optimal conditions cannot be met and thus higher wear results. Even with Inverted cups experiencing edge-loading only intermittently in each cycle, test-3 produced 5-fold greater wear than our prior Anatomic study. This more than satisfied our 3rd hypothesis that MOM wear rates would be doubled under edge-loading.

Our 60mm MOM wear-rates (Inverted cups) averaged $2 \mathrm{~mm}^{3} / \mathrm{Mc}$ over 5-Mc test with a ratio of $86 \%$ cup to total MOM wear. The prior Anatomic test produced a cup wear ratio that varied from $68 \%$ in normal trending to $85 \%$ during "breakaway" wear trends [17]. The latter value was virtually identical to that in our edge-loaded test-3, likely signifying a trigger such as partial lubrication failure. There was also a dramatic correspondence of wear trends with $60 \mathrm{~mm}$ Inverted cups run dynamically inclined over 5-Mc with $40 \mathrm{~mm}$ cups in Anatomical mode and run at fixed $60^{\circ}$ inclination. [14]. Clearly this could be coincidental due to the many experimental differences. However, our observation was that MOM bearings run under such edge-loading conditions did not provoke adverse wear as reported by others. Our data represented stable trends with wearrates that did not turn lubricants black. These data suggest that additional conditions need to be present to provoke adverse wear, such as surgical and patient-related risks that may contribute to joint laxity, impingement, head subluxation, release of large metal particles, etc.

\section{Appendix A}

The size of head and cup wear patterns is produced by the simulator mechanics and this ratio is $\mathrm{x} 3.87$ for the orbital machines. Thus, in our prior $60 \mathrm{~mm}$ Anatomic test, cup and head wear-patterns averaged $442 \mathrm{~mm}^{2}$ and $1668 \mathrm{~mm}^{2}$, respectively, giving the experimentally derived ratio $x 3.77$. Knowing the angle subtended by the cup wearpattern $\left(45.6^{\circ}\right)$ and cup flexion-angle $\left(46^{\circ} \mathrm{arc}\right)$, the summated angle $\left(91.6^{\circ}\right)$ can be shown by spherical geometry to to be subtended by a head wear-pattern of $1712 \mathrm{~mm}^{2}$ area. The measured and calculated wear-areas on heads agreed within $44 \mathrm{~mm}^{2}$ ( $<3 \%$ difference), revealing that wear patterns on hip bearings were predictable.

In our previous study, a MOS-algorithm was created to define sizes of cup wear-patterns and clinical risks of edgeloading. Equations governing edge loading in Anatomic test mode (Fig. A1) were presented as,

\section{Equation-1: $\quad \mathbf{L}+\mathbf{P}+\mathbf{M O S}+\mathbf{A} / \mathbf{2}=\mathbf{9 0}{ }^{\circ}$ Equation-2: $\quad \mathbf{2} * \mathbf{P}+\mathbf{F}=\mathbf{1 8 0}^{\circ}$}

Where,

Angle $(\mathrm{A})=$ wear-pattern angle from simulator data. [16] Angle $(\mathrm{F})=$ cup-face angle in sub-hemispherical cup. Angle $(\mathrm{L})=$ cup inclination in horizontal plane of simulator

Angle $(\mathrm{MOS})=$ angle between cup rim and wear pattern Angle $(\mathrm{P})=$ rim-profile angle of sub-hemispherical cup

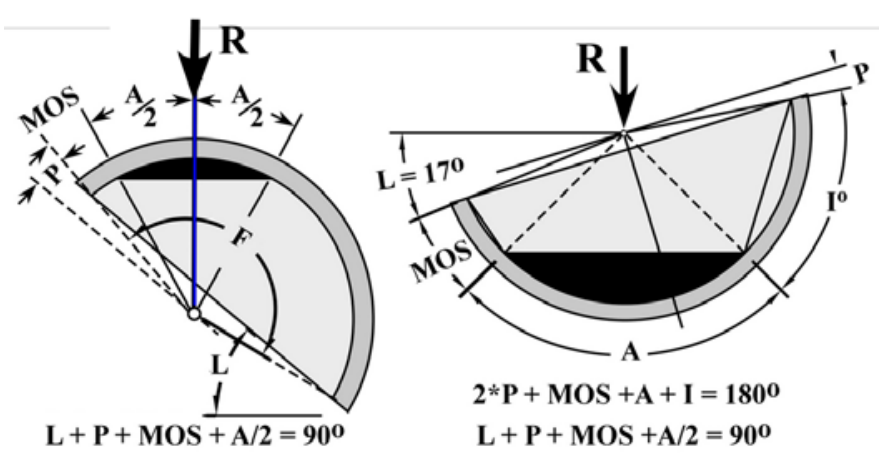

The critical cup angle $(* \mathrm{~L})$ can be defined as that inclination where the edge of the wear pattern becomes juxtaposed to cup rim, i.e. MOS angle = zero and given by,

Equation-3: $\quad * \mathbf{L}=\mathbf{9 0}{ }^{\circ}-(\mathbf{P}+\mathbf{A} / \mathbf{2})$ 


\section{Degree of edge-wear (Figure 3) can be defined as}

\section{Equation-4: $\quad \mathbf{E W} \%=\mathbf{1 0 0} *(\mathbf{A}-\mathbf{B}) / \mathbf{A}$}

The notable difference between Inverted and Anatomic test modes is that in the former the cup inclination angle varies dynamically whereas in the latter the cup inclination is held fixed. However, analysis for edge-loading condition is essentially the same for both Inverted and Anatomic modes.

\section{Acknowledgements}

This project was supported by FDA contracts on preclinical (simulator) validation studies of Metal-on-Metal (MOM) Bearings (FDA-1090372 and 1119682).

\author{
SUBMISSION HISTORY \\ Submitted August 16, 2017 \\ Reviewed September 14, 2017 \\ Revised September 21, 2017 \\ Accepted September 22, 2017 \\ Published September 30, 2017

\section{AUTHOR AFFILIATIONS} \\ 1 lan Clarke, PhD \\ Professor in Research, Dept. Orthop., Loma Linda University Medical Center \\ 11406 Loma Linda Drive, Loma Linda University, Loma Linda, CA 92354 US \\ 2 Julia Shelton, $\mathrm{PhD}$ \\ School of Engineering and Materials Science, Queen Mary University of London, \\ London, UK \\ 3 John Bowsher, PhD \\ Anterior Spine Devices Branch, FDA, Silver Springs, Washington, DC \\ 4 Christina Savisaar, PhD \\ Orthopedic Joints Devices Branch, FDA, Silver Springs, Washington DC \\ 5 Thomas Donaldson, MD \\ Donaldson Arthritis Research Foundation, 900 E. Washington Street, Suite 200 \\ Colton, CA 92324 US \\ (Direct inquires to lan Clarke, ithipgeek15@yahoo.com)
}

\section{AUTHOR DISCLOSURES}

The authors declare that there are no disclosures regarding the publication of this paper.

\section{COPYRIGHTS}

(c) 2017 Clarke, Shelton, Bowsher, Savisaar, Donaldson. All rights reserved. Authors retain copyright and grant the journal right of first publication with the work. Reconstructive Review is an open access publication and follows the Creative Commons AttributionOPEn 6 access NonCommercial CC BY-NC. This license allows anyone to download works, build upon the material, and share them with others for non-commercial purposes as long as they credit the senior author, Reconstructive Review, and the Joint Implant Surgery \& Research Foundation (JISRF). An example credit would be: "Courtesy of (senior author's name), Reconstructive Review, JISRF, Chagrin Falls, Ohio".

\section{References}

1. ISO 14242-1 (2002) Implants for surgery -- Wear of total hip-joint prostheses -Part 1: Loading and displacement parameters for wear-testing machines and corresponding environmental conditions for test.

2. Williams S, Leslie I, Isaac G, Jin Z, Ingham E, Fisher J. Tribology and wear of metal-on-metal hip prostheses: influence of cup angle and head position. J Bone Joint Surg Am. 2008;90 Suppl 3:111-117.

3. Leslie I, Williams S, Brown C, Isaac G, Jin Z, Ingham E, Fisher J. Effect of bearing size on the long-term wear, wear debris, and ion levels of large diameter metal-on-metal hip replacements-An in vitro study. J Biomed Mater Res B Appl Biomater. 2008;87:163-172.

4. Lee R, Essner A, Wang A. Tribological considerations in primary and revision metal-on-metal arthroplasty. J Bone Joint Surg Am. 2008;90 Suppl 3:118-124.

5. McMinn, D. Treacy, R. Lin, K. Pynsent, P. (1996). Metal on metal surface replacement of the hip. Experience of the McMinn prosthesis. Clin. Orthop. 329 Suppl., pgs S89-98.

6. Amstutz, H. C. Campbell, P. McKellop, H. Schmalzreid, T. P. Gillespie, W. J. Howie, D. Jacobs, J. Medley, J. Merritt, K. Metal on metal total hip replacement workshop consensus document. Clin. Orthop. 329 Suppl., pgs S297-303.

7. Hart, A. J. Hester, T. Sinclair, K. Powell, J. J. Goodship, A. E. Pele, L. Fersht, N. L. Skinner, J. The association between metal ions from hip resurfacing and reduced T-cell counts (2006). JBJS-Br. 88(4), 449-54.

8. McLardy-Smith, P. Steffen, R. T. Pandit, H. Murray, D. W. Gill, H. S (2006) Metal-on-metal hip resurfacing: America, where are you? Orthopedics 29:795-6.

9. Langton DJ, Jameson SS, Joyce TJ, Webb J, Nargol AV. The effect of component size and orientation on the concentrations of metal ions after resurfacing arthroplasty of the hip. J Bone Joint Surg Br. 2008;90:1143-1151.

10. Glyn-Jones, S., Roques, A., Gill, R.Taylor, A., Whitwell, D., Esposito, C., Walter, W., Tuke, M., Murray, D.Metal on metal hip resurfacing arthroplasty-related pseudotumours are associated with increased bearing surface wear, caused by impingement and edge-loading. In 56th Annual Meeting of the ORS, poster \#2164, 2010.

11. Morlock, M. M., Bishop, N. E., Zustin, J., Hahn, M. , Ruther, W. Amling, M Modes of Implant Failure After Hip Resurfacing: Morphological and Wear Analysis of 267 Retrieval Specimens. J Bone Joint Surg (Am):90;89-95, 2008.

12. Leslie, I. J. Williams, S. Isaac, G. Ingham, E. Fisher, J. (2009). High cup angle and microseparation increase the wear of hip surface replacements. Clin. Ortho. 467(9), 2259-65.

13. Hu, XQ Jeffers, J Roques, A Taylor, A Tuke, M.(2011). In vitro wear study of MOM and COM Hip Prostheses with High Cup Angle. In Orthop Res. Soc, poster 1163.

14. Angadji A, Royle M, Collins SN, Shelton JC. Influence of cup orientation on the wear performance of metal-on-metal hip replacements. Proc Inst Mech Eng $\mathrm{H}$. 2009;223:449-457.

15. Clarke IC, Donaldson TK, Burgett MD, Smith EJ, Bowsher J, Savisaar C, John A, Lazennec JY, McPherson E, Peters CL. Normal and Adverse Wear Patterns Created In-vivo on MOM Surfaces - a retrieval study representing four vendors. In: Kurtz SM, Greenwald SA, Mihalko WM, Lemons JA, ed. Metal-on-Metal Total Hip Replacement Devices. West Conshohocken, PA: ASTM International; 2013:157-192.

16. Clarke IC, Lazennec JY. Margin-of-safety Algorithm used with EOS imaging to Interpret MHRA Warning for Small-diameter MOM Hip Arthroplasty. Reconstructive Review. 2015;5:13-21.

17. Bowsher JG, Clarke IC, Williams PA, Donaldson TK. What is a "normal" wear pattern for metal-on-metal hip bearings? J Biomed Mater Res B Appl Biomater. 2009;91:297-308

18. Koper MC, Mathijssen NMC, Claasen HHR, Witt F, M MM, Vehmeijer SBW. Pseudotumor after bilateral ceramic-on-metal total hip arthroplasty. J Bone Joint Surg: JBIS Case connect; 2014

19. Chan, F. W. Bobyn, J. D. Medley, J. B. Krygier, J. J. Yue, S. Tanzer, M.(1996) Engineering issues and wear performance of metal on metal hip implants. Clin. Ortho. 333:96-107.

20. Anissian, H. L. Stark, A. Gustafson, A. Good, V. Clarke, I. C. (2009). Metal-onmetal bearing in hip prosthesis generates 100 -fold less wear debris than metal-onpolyethylene. Acta Orthop. Scand. 70(6): 578-82.

21. Park, S. H. McKellop, H. Lu, B. Chan, F. W. Chiesa, R.(1999). Wear morphology of metal-metal implants: Hip simulator tests compared with clinical retrievals. In "Metasul, A Metal-on-Metal Bearing", Eds. Rieker, Claude Windler, Markus and Wyss, Urs, Pub: Hans Huber, Berne Switzerland. 